\title{
Most Common Pathologies in Primary Care
}

\author{
Ibrahim Rudhani, Naim Morina*, Shkelqim Kuçi and Ahmet Avdullahu I \\ Medicinal Faculty, University of Prishtina, Kosovo and University Clinical Center of Kosovo
}

Received: June 20, 2018; Published: July 03, 2018

*Corresponding author: Naim Morina, Specialist of Internal Medicine Medicinal Faculty, University of Prishtina, Clinical Neophrology and Hemodialysis UCCK Kosovo, Hospital Circle n.n. 10000 Pristina, Kosovo

\begin{abstract}
Introduction: Primary healthcare in Kosovo is provided in accordance with policies, plans, and standards set forth in the sub-legal act issued by the Ministry of Health. In the treatment of health problems in primary health care we encounter a variety of pathologies, among them mostly acute tonsilopharyngitis, essential arterial hypertension, backache diseases, gastroenteritis and diarrhea, as well as influenza and diabetes mellitus.
\end{abstract}

Purpose of the Paper: The purpose of this paper is to provide practitioners and professionals with a comprehensive view of pathologies that occur most frequently in Primary Practice at Main Family Medical Centers No. VI in Prishtina by relying on the results that derived from research. This involves statistical analysis of the incidence by sex and age for certain pathologies, including the incidence by appearance frequency of influence during the months of the year.

Methods: Statistical Diagnostic Data on the Morbidity of Population from the Family Medicine Center no. VI-Prishtina, for the period January 1, 2017 to December 31, 2017 are used in this paper. In this retrospective study, 4720 cases of the, above mentioned pathologies have been reported. Patients diagnosed with acute tonsilopharyngitis, gastroenteritis and diarrhea, diabetes mellitus, essential arterial hypertension, back ache causing diseases and influenza during 2017, participated in this paper.

Results: In the period from January 1, 2017 to December 31, 2017, 17922 patients were diagnosed in Main Family Medical Centers No. VI-Prishtina. The frequency of the diseases emphasizes 1898 (40.21\%) cases of acute tonsilopharyngitis, 905 (19.17\%) cases with essential arterial hypertension, $762(16.14 \%)$ cases with back ache causing diseases, $509(10,78 \%)$ with gastroenteritis and diarrhea, 361 (7.65\%) cases with influenza and 285 (6.04\%) cases with diabetes mellitus.

Conclusion: The study shows that from these pathologies the appearance frequency in percentage from 4720 cases results in $40.16 \%$ with acute tonsillopharyngitis, $19.17 \%$ with essential arterial hypertension, $16.14 \%$ backache causing diseases, $10.78 \%$ with gastroenteritis and diarrhea, $7.65 \%$ with influenza and $6.04 \%$ with diabetes mellitus.

Keywords: Essential Arterial Hypertension; Influenza; Gastroenteritis and Diarrhea; Diabetes Mellitus; Acute Tonsillopharyngitis; Backache Causing Diseases

\section{Introduction}

Primary health care in Kosovo is ensured in accordance with the policies, plans and standards set out by sub-legal act issued by the Ministry.

These services are provided by public, private and publicprivate health institutions. The ministry supervises and regulates the implementation of health care at the three institutional levels, such asthe public, private, and public-private institutions. The Primary healthcare institutions emphasize the main family medical center with the components defined by sub-legal act issued by the Ministry such as:

\section{Primary Health Care Includes}

a) Promotion of health, early detection, diagnosis, treatment and rehabilitation of the diseases, as well as minor surgical interventions. b) Making systematic visits to children and young people at all levels of education such as primary, secondary, and high education in the territory of the municipality.

c) Preservation and promotion of public health, including vaccine prophylaxis and chemio-prophylaxis in accordance with the law.

d) Promotes oral health and dental health care.

e) Diagnosis of patients and treatment of tuberculosis.

f) Organization of emergency medical services as part of the unique system of services in all three levels of health care.

g) Mother and child health care services and planning services.

h) Mental health services. 
Municipalities are responsible for the implementation of Primary Health Care by giving priority to the implementation of preventive measures through the implementation of the concept of a medicinal family [1-4]. Kosovo has 36 municipalities, where KPS institutions are located, respectively the Main Family Medical Centers It should be noticed that besides the Main Family Medical Centers, among the institutions that provide primary health care are Family Medicine Centers (Family Medicine Center) and Family Medicine Points (PMF). In some municipalities within the F's there are also out-of-hospital Maternity and Women's Welfare Centers.

Family Medicine consists of a group of specialized doctors in this area. The family doctor offers advice and assistance for all illnesses in general and exerts the following competences:

a) Provides medical advice on health protection and identifies diseases;

b) Diagnoses the disease and treating the patient;

c) Instructs and treats preventive disease treatment.

During the treatment of health problems in primary health care we encountered the variety of pathologies, among which were mainly acute tonsilopharyngitis, essential arterial hypertension, backache causing diseases, gastroenteritis and diarrhea, influenza and diabetes mellitus [5-8].

\section{Study Design \\ Purpose of the Paper}

The purpose of this paper to provide practitioners and professionals with a more comprehensive overview over the pathologies that occur most frequently in Primary Medicine (Family Medicine Center Besi), relying upon the incidences by sex and age for certain pathologies (acute tonsilopharyngitis, essential arterial hypertension, gastroenteritis and diarrhea, diabetes mellitus, backache causing diseases and influenza). In addition, incidence by appearance frequency of influenza during the months of the year [9-12].

\section{Research Methods}

The statistical data on the morbidity of the population of the Besi Family Medicine Center were used from the period 01 January 2017 to 31 December 2017. In this retrospective study, 4720 cases of the described pathologies have been reported [13-15].

The cases of patients diagnosed with acute tonsillopharyngitis, gastroenteritis and diarrhea, diabetes mellitus, essential arterial hypertension, backache causing diseases and influenza were diagnosed during 2017 [16].

Demographic and morbidity characteristics of the researched population (gender, age).

a) Data related to the aforementioned pathologies.

b) A Comparison between the age and gender was made.

c) It was explored the appearance of influence over the months of the year. d) The research deals with the type of retrospective studies, data have been obtained from the main family medicine center in Prishtina, for the family medicine center Besi.

e) The obtained results are presented in tables and graphs.

\section{Results}

During the period from January 1, 2017 to December 31, 2017, 17922 patients were diagnosed in Family Medicine Center No. VI Prishtina. 4720 patients participated in the research study. The most frequently investigated ailments were in female patients $(2568,54.41 \%)$ than in males $(2152,46.59 \%)$ [17-22].

Based on age, the diseases investigated reported that, 226 patients were $<1$ year old, 499 patients $1-4$ years old, 431 patients 5-9 years old, 262 patients 10-14 years old, 241 patients 15-19 years old , 352 patients 20-24 years old, 409 patients 25-34 years old, 571 patients $35-44$ years old, 596 patients $45-54$ years old, 513 patients 55-64 yeasr old, 517 patients over 65 years of age, and 3 cases of unknown age $[23,24]$.

Among the 6 (pathological) diseases investigated in terms of frequency, there are 1898 (40.21\%) cases of acute tonsilopharyngitis, $905(19.17 \%)$ cases with essential arterial hypertension, 762 (16.14\%) cases with backache diseases, 509 $(10.78 \%)$ cases with gastroenteritis and diarrhea, 361 (7.65\%) cases with influenza and 285 (6.04\%) cases with diabetes mellitus [25].

Regarding the investigation of diabetes mellitus, the most affected age during 2017 was 55-64 years old and with a lot of attacked females [26].

For essential arterial hypertension, the most affected age in 2017 was 55-64 years of age and mostaffected was the female gender [27].

For influenza, the most affected age in 2017 was 20-34 years of age and females were more affected. Also during the early autumn (October), spring (March, April) and winter (January, February) we have the most appearance of it [28].

The results indicate that the most affected age in 2017 for Gastroenteritis and diarrhea has been from 1 to 4 years, where women are more effected than men. However, we noted a significant decrease of cases with age.

For acute tonsilopharyngitis, the most affected age during 2017 is from 1 to 9 years old. Also here women are more often affected than men [29].

As for the backache causing disesases, the increasing incidences are positively associated with age and women seem to be more often affected than men.

Out of a total of 17,922 patients in the family home trust 10,102 $(56.37 \%)$ were females and $7820(43.63 \%)$ male. Where 6 Diseases Participate with 4720 (26.34\%) cases out of the total, with 2568 (14.33\%) female cases and 2152 (12.01\%) male cases (Tables 1 \& 2) (Graphics 1-3) [30,31]. 


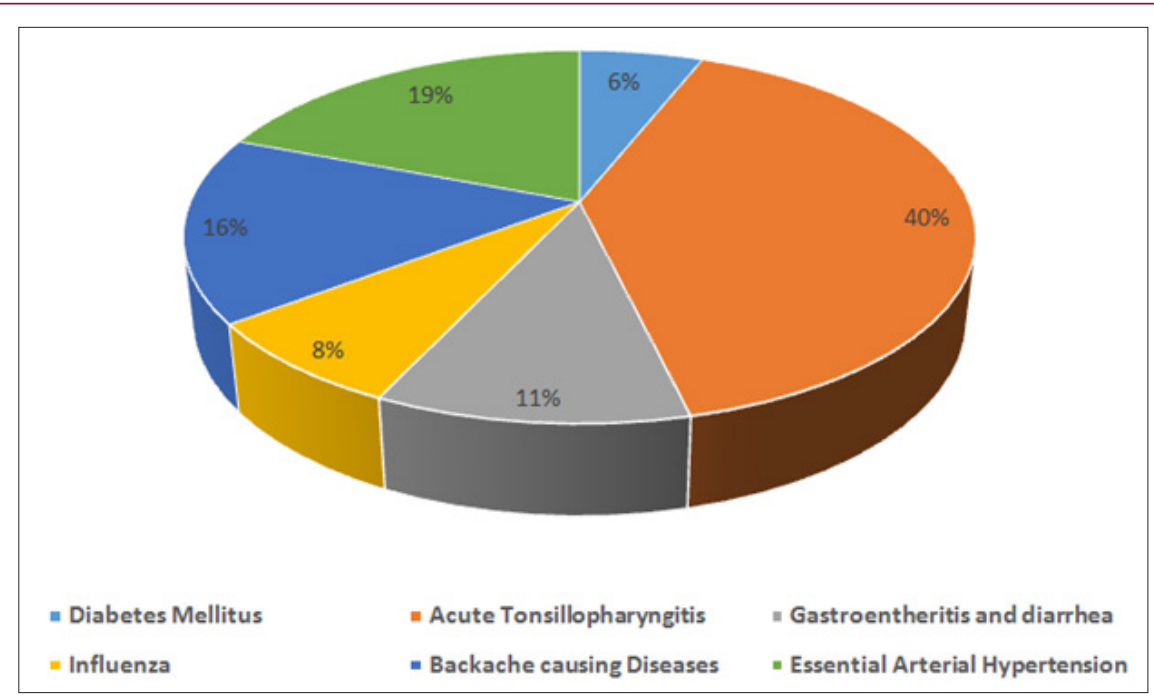

Graphic 1: Graphic appearance of the common diseases results as above.

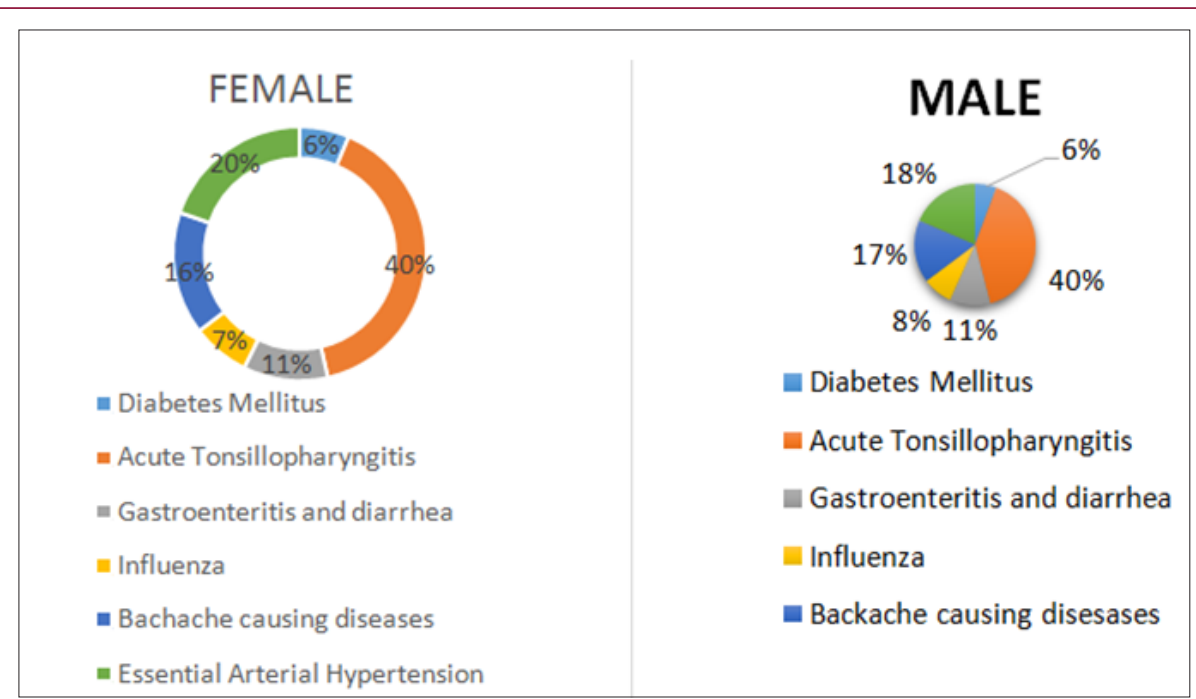

Graphic 2: Graphic appearance of the 6 common diseases based on gender.

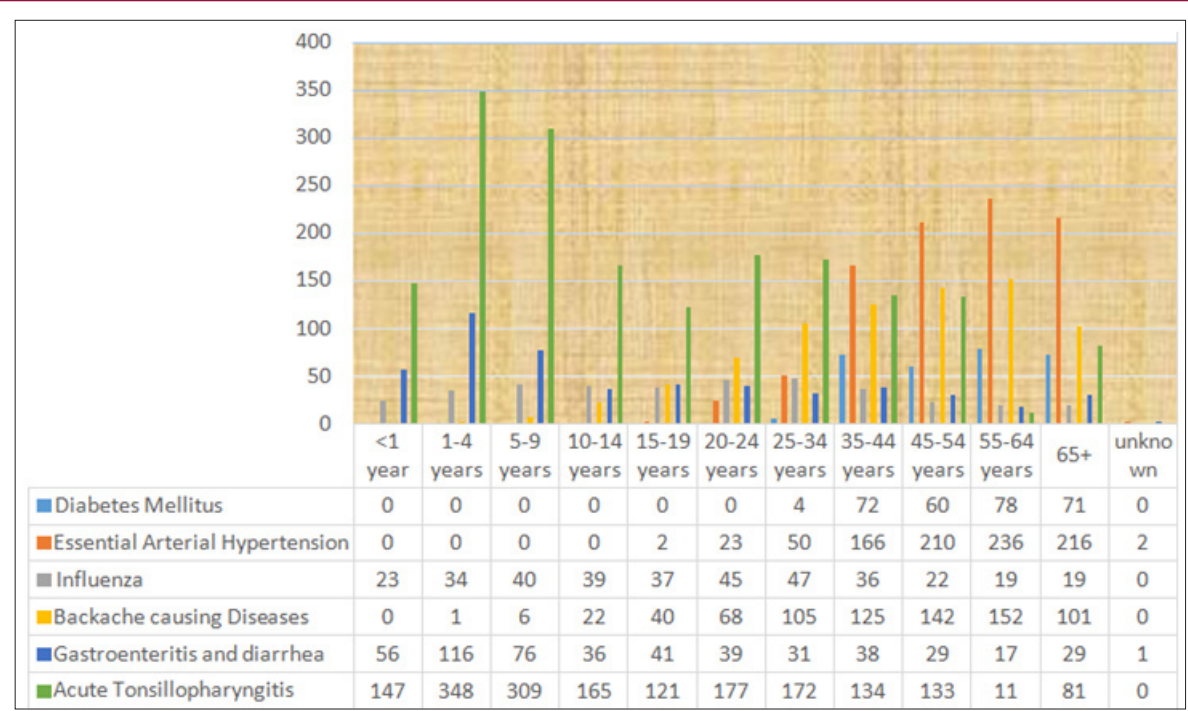

Graphic 3: Graphic appearance of the most common diseases based on age. 
Table 1: Total patients number from QMF Nr.VI in Prishtina based on gender and total number of patients with the most common pathologies.

\begin{tabular}{|c|c|c|c|}
\hline & Total (\%) & Female (\%) & Male (\%) \\
\hline Nr. of patients & $17922(100)$ & $10102(56,37)$ & $7820(43,63)$ \\
\hline Most common diseases & $4720(26,34)$ & $2568(14,33)$ & $2152(12,01)$ \\
\hline
\end{tabular}

Table 2: Total Nr. of patients sorted by the 6 common pathologies.

\begin{tabular}{|c|c|c|c|c|c|c|c|}
\hline & Total Cases & $\begin{array}{c}\text { Acute } \\
\text { Tonsilopharyngitis }\end{array}$ & $\begin{array}{c}\text { Essential } \\
\text { Arterial } \\
\text { Hypertension }\end{array}$ & $\begin{array}{c}\text { Backache } \\
\text { Causing } \\
\text { Diseases }\end{array}$ & $\begin{array}{c}\text { Gastroenteritis } \\
\text { and Diarrhea }\end{array}$ & $\begin{array}{c}\text { Influenza } \\
\text { Mellitus }\end{array}$ \\
\hline Nr. of patients & 4720 & 1898 & 905 & 762 & 509 & 361 & 285 \\
\hline Percentage & $100 \%$ & $40.21 \%$ & $19.17 \%$ & $16.14 \%$ & $10.78 \%$ & $7.65 \%$ & $6.04 \%$ \\
\hline
\end{tabular}

From the diagram we see that the most attached age during attached (Graphic 4). 2017 was from 55-64 years of age and the female gender was more

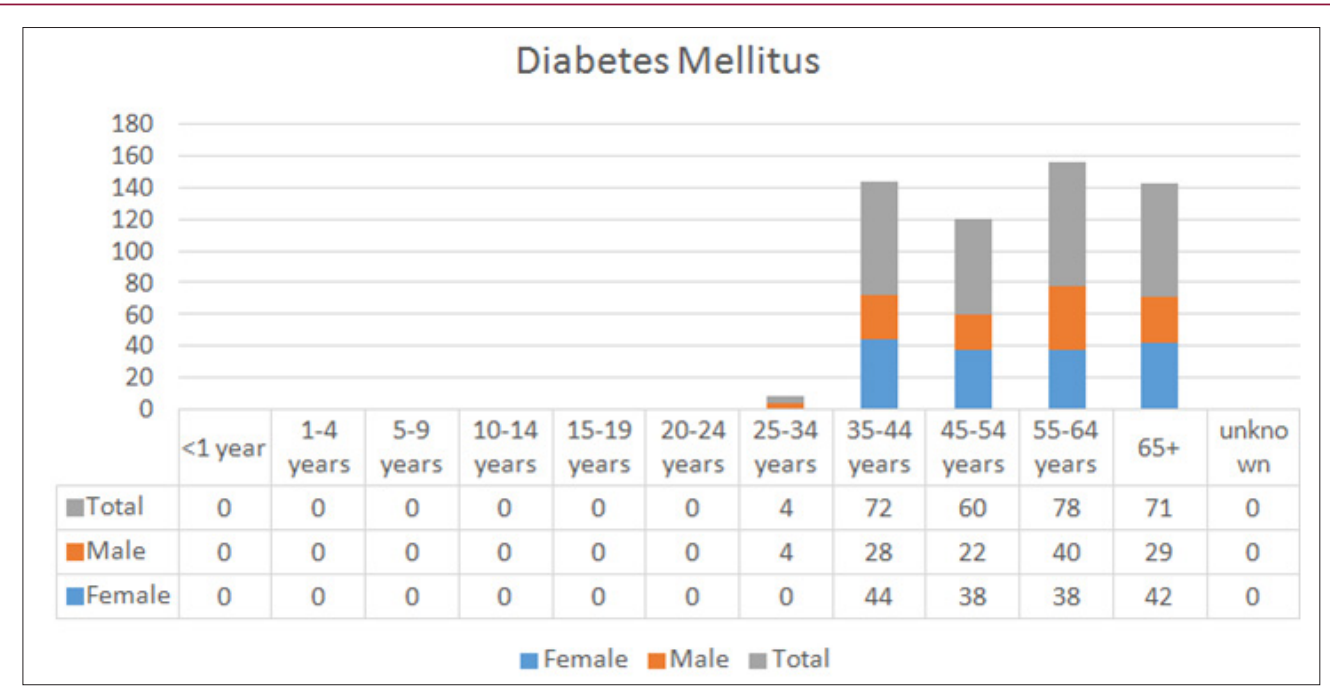

Graphic 4: Graphic appearance for Diabetes Mellitus based on age and gender.

As we see the most attached age for Essential Arterial was the female gender (Graphic 5). Hypertension, during 2017 is 55-64 years of age and more affected

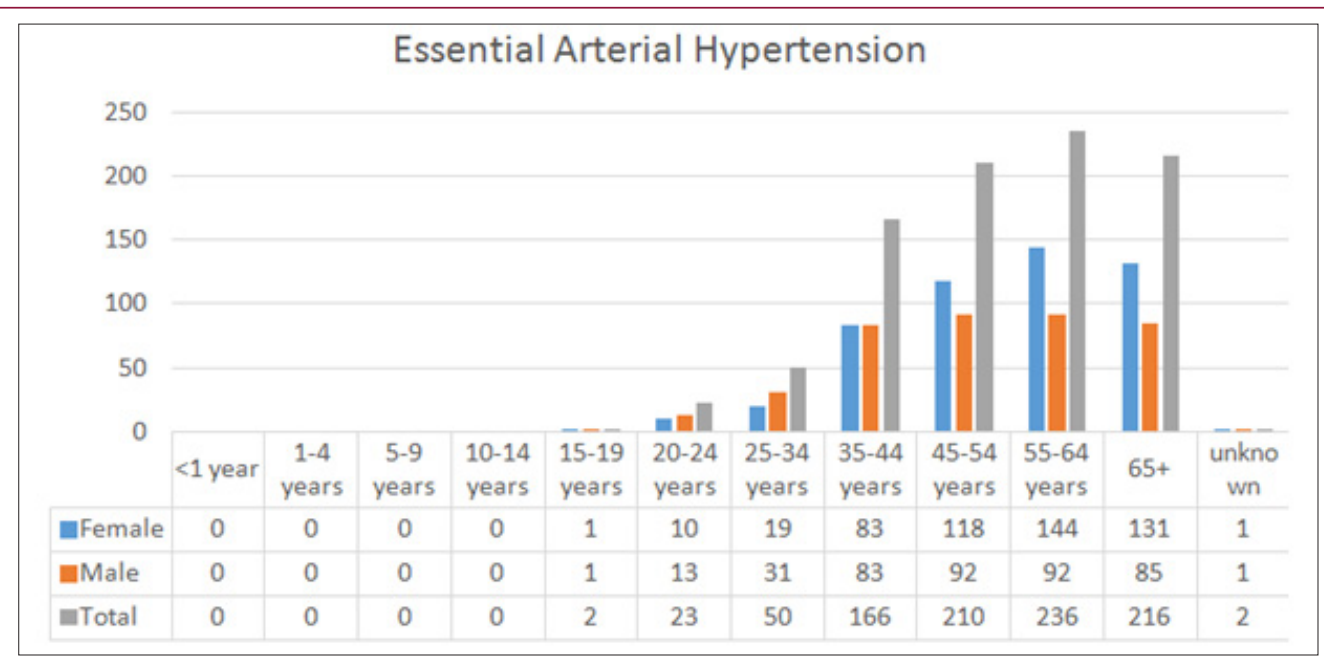

Graphic 5: Graphic appearance of Essential Arterial Hypertension based on age and gender.

From the diagram we see that the most attached age with influenza during 2017 was from 20-34 years of age and the most attacked gender was the female one. Worth mentioning is the distribution of the disease without large differences based on the age (Graphic 6). 


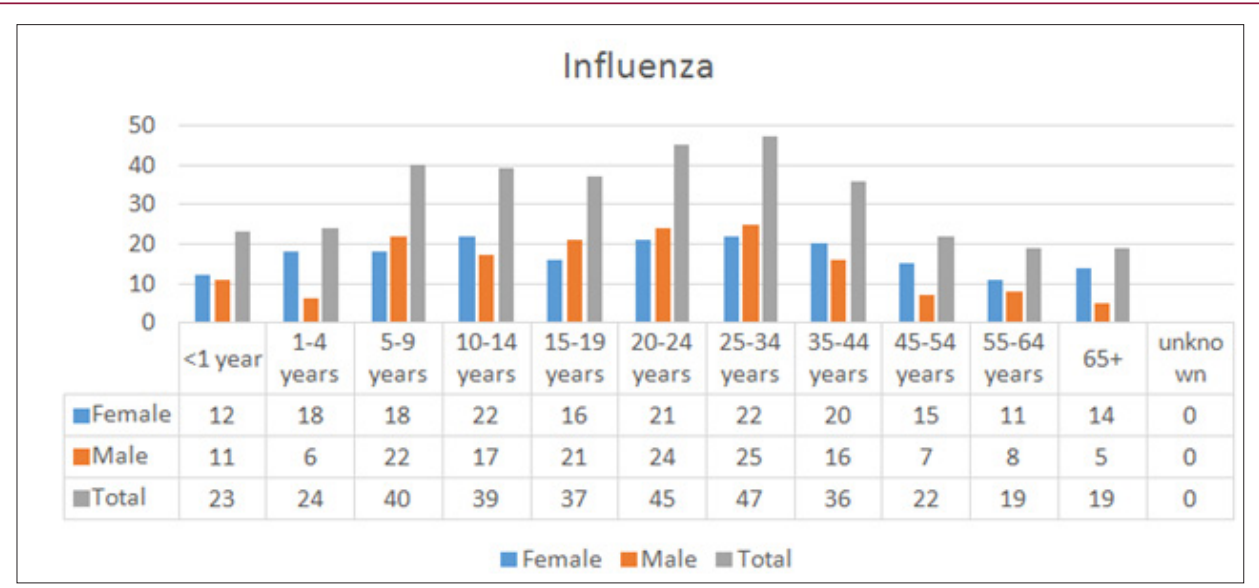

Graphic 6: Graphic appearance of influenza based on age and gender.

Important to mention that the most cases of influenza appears (January, February) (Graphic 7). on early autumn (October), spring (March, April) and winter

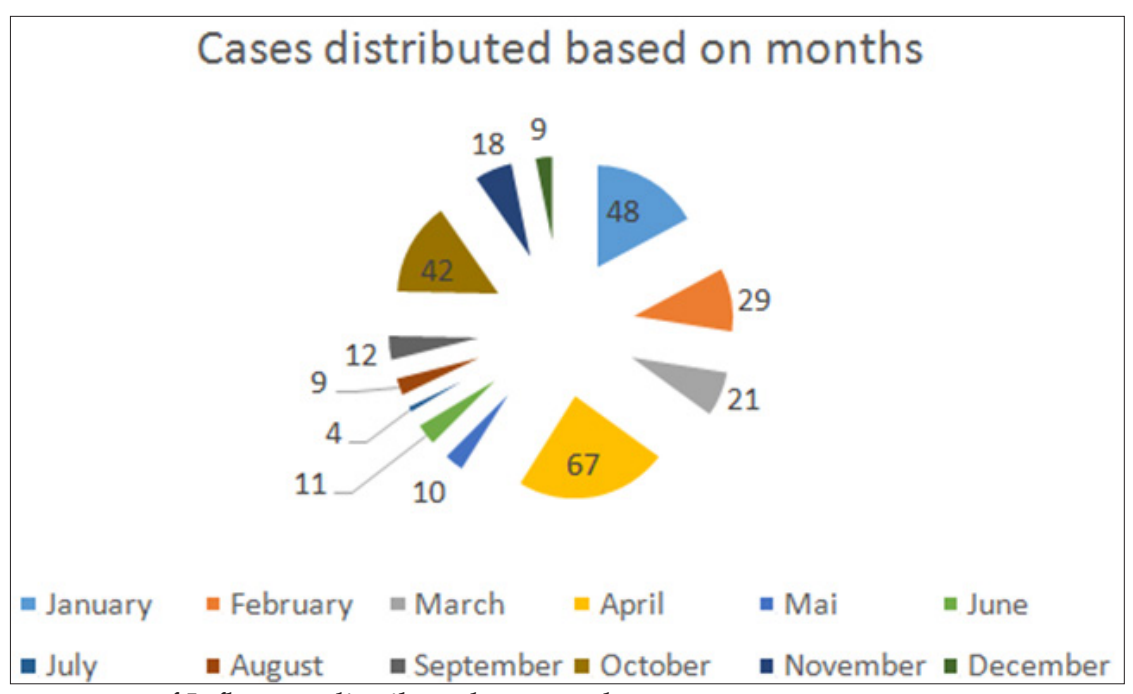

Graphic 7: Graphic Appearance of Influenza distributed on months.

From the diagram we see, for Gastroenteritis and diarrhea that the most attached age, during 2017 is from 1-4 years of age and the most attached gender was the female gender and we can see while increasing in age there is a decrease on cases with this disease (Graphic 8).

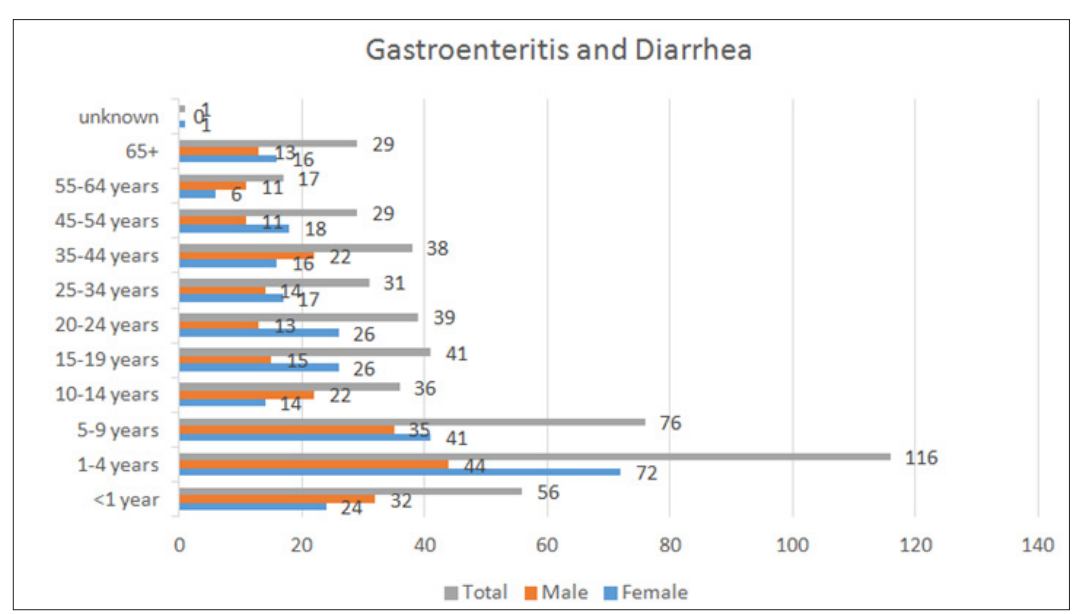

Graphic 8: Graphic Appearance of Gastroenteritis and Diarrhea based on age and gender. 
The Diagram shows that for Acute Tonsillopharyngitis during was the female gender (Graphic 9). 2017 more affected was the age from 1-9 years and most attached

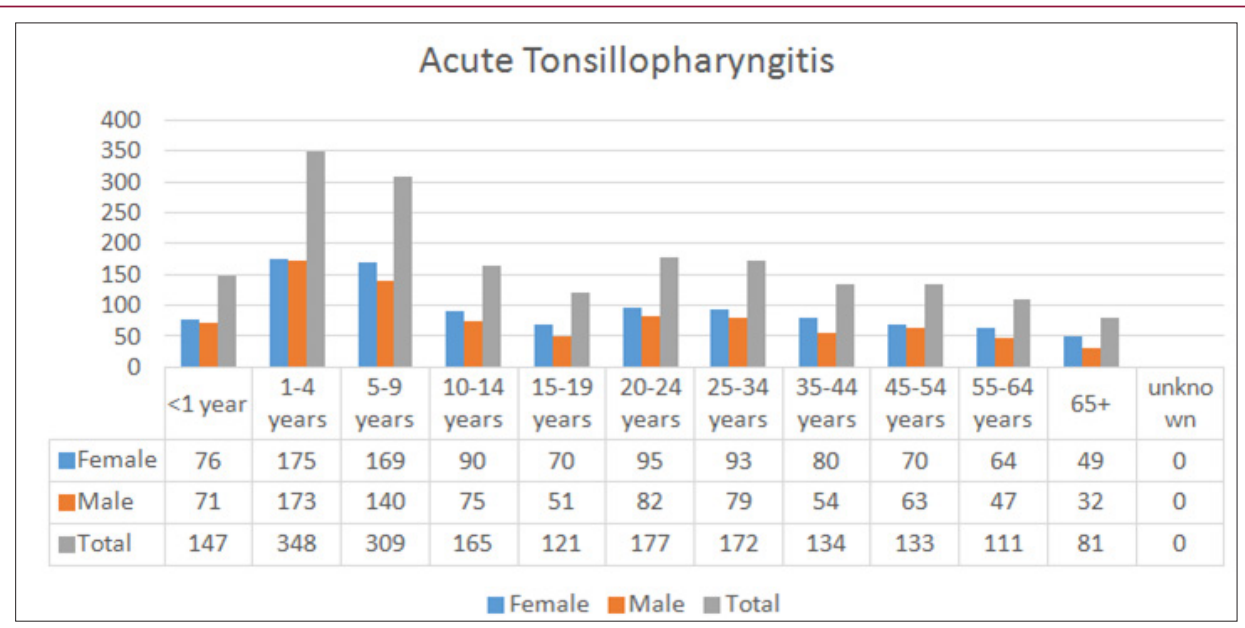

Graphic 9: Graphic appearance of Acute Tonsillopharyngitis based on age and gender.

The Diagram shows that for Backache causing Diseases during attached was the female gender (Graphic 10). 2017 the number of cases increased on elderly ages and more

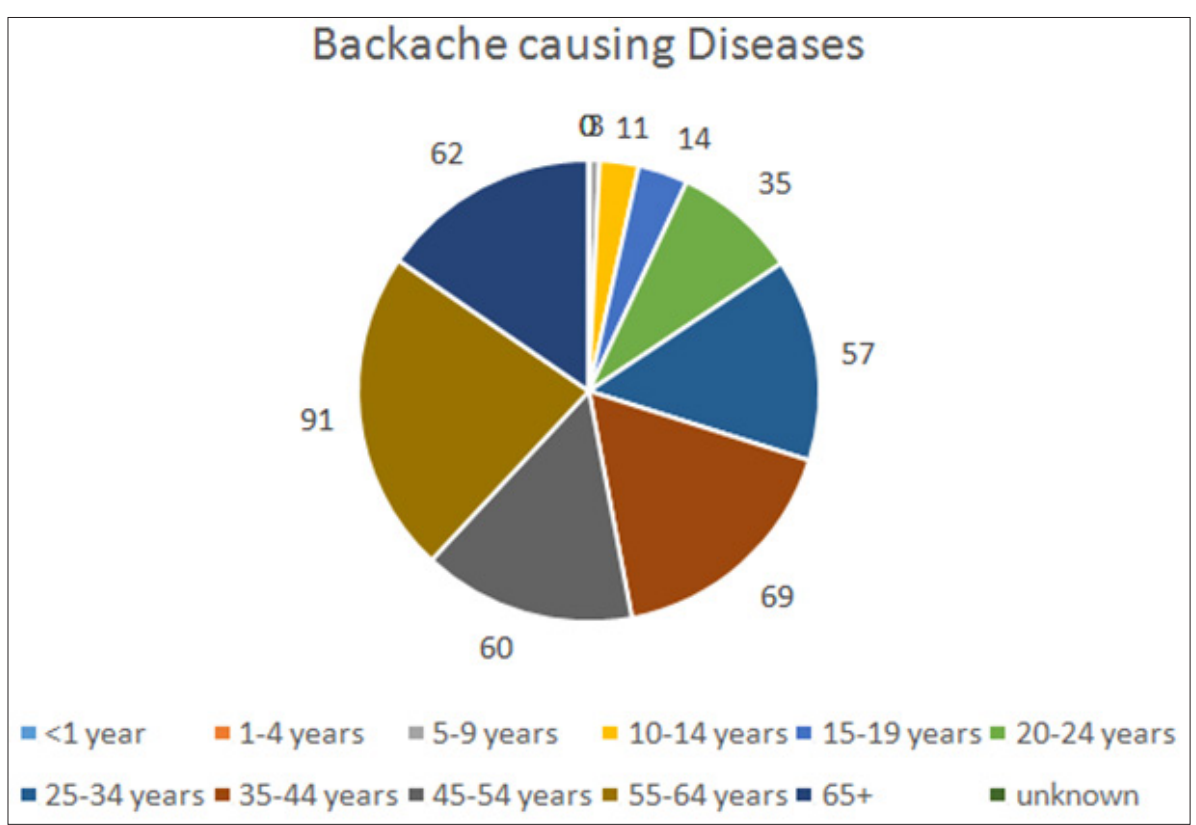

Graphic 10: Graphic appearance for Backache causing Diseases based on gender and age.

\section{Discussion}

From the most frequent problems in primary health care at QMF No. VI-Prishtina, according to the data surveyed we gained and understand that out of 17922 diagnosed patients, 4720 patients presented one of the 6 pathologies. The first place, within these pathologies was acute tonsillopharyngitis, which occurred with 1898 cases in total, of which 1031 patients were female patients and 867 male patients. The Second pathology was the Essential arterial hypertension with 905 patients, 507 female patients and 398 male patients. The third pathology was Backache causing Diseases with 762 cases, out of which 402 female and 360 male patients. It Continues with gastroenteritis and diarrhea with a total of 509 cases, with 277 female patients and 232 male patients. Influenza with 361 patients, of whom 189 female and 172 male patients. Finally, 285 cases with diabetes mellitus, 162 patients belong to the female gender and 123 male gender [32-34].

Based on age, we understand that for acute tonsillopharyngitis the most affected age is 1-4 years, for essential Arterial Hypertension 55-64 years of age, for Backache causing Disease 55-64 years of age, for Gastroenteritis and diarrhea the age from 1-4. For Influenza the age of 25 to 34 years, although there is no significant difference between the ages in terms of its appearance. While diabetes Mellitus is most commonly affects the age of 55-64 years [35]. 
If we compare the primary services of the Swiss medical system, we understand that the organization of primary services in that system is based on independent private practices, provided by specialists in the field of general medicine and internal medicine which are distributed by geographical needs, also divided into cantons. Based on the statistics of 2016, we can conclude that from the diagnosed cases $11.6 \%$ are with psychological disorders, $11.5 \%$ with central nervous system and sensory diseases, 10.9\% with cardiovascular system problems, 9.8\% with loco-motor system problems [36,37].

\section{Conclusion}

The research has shown that the most common diseases in primary health care are: acute tonsillopharyngitis, Essential Arterial Hypertension, Gastroenteritis and diarrhea, Backache diseases, Influenza and Diabetes Mellitus.

As shown in the study, the appearance frequency of these pathologies from 4720 cases results in $40.16 \%$ with acute tonsilopharyngitis, $19.17 \%$ with Essential Arterial Hypertension, $16.14 \%$ with backache causing diseases, $10.78 \%$ with gastroenteritis and diarrhea, $7.65 \%$ with influenza and $6.04 \%$ with diabetes Mellitus.

As the statistics show, primary health care presents a very important link in preventing, diagnosing, treating properly, and avoiding the possible complications associated with the diseases being explored.

\section{References}

1. Whelton PK, Carey RM, Aronoë WS, Casey DE, Collins KJ, et al. (2017) ACC/AHA/AAPA/ABC/ACPM/AGS/APhA/ASH/ASPC/NMA/PCNA Guideline for the prevention, detection, evaluation, and management of high blood pressure in adults. A report of the American College of Cardiology/American Heart Association Task Force on clinical practice guidelines, Hypertension.

2. http://www.heart.org/HEARTORG/Conditions/HighBloodPressure/ KnowYourNumbers/Understanding-Blood-Pressure-Readings UCM_301764_Article.jsp\#.Wo2kU6jOXIV

3. http://www.heart.org/HEARTORG/Conditions/HighBloodPressure/ UnderstandSymptomsRisks/What-are-the-Symptoms-of-High-BloodPressure_UCM_301871_Article.jsp\#.Ëo2kV6jOXIV

4. Mancia G, Fagard R, Narkieëicz K, Redon J, Zanchetti A, et al. (2013) $2013 \mathrm{ESH} / \mathrm{ESC}$ guidelines for the management of arterial hypertension. European Heart Journal 34(28): 2159-2219.

5. Mathers CD, Loncar D (2006) Projections of global mortality and burden of disease from 2002 to 2030. PLoS Med 3(11): e442.

6. https://www.webmd.com/diabetes/guide/types-of-diabetesmellitus\#2

7. https://www.diabetes.co.uk/difference-between-type1-and-type2diabetes.html
8. https://ww.medicinenet.com/diabetes_mellitus/article.htm\#diabetes_ type_1_and_type_2_definition_and_facts

9. American Diabetes Association (2011) Standards of Medical Care in Diabetes-2011. Diabetes Care 34: S11-61.

10. https://dtc.ucsf.edu/living-with-diabetes/complications/\#acute

11. Papadakis MA (2014) Current Medical Diagnosis \& Treatment. Neë York, NY: The McGraw-Hill Companies, USA.

12. http://flexikon.doccheck.com/de/Influenza\#Definition

13. http://goodtimes.sc/columns/wellness/truth-about-the-flu/

14. http://www.md-health.com/Influenza-B.html

15. https://www.medicinenet.com/influenza/article.htm\#flu_influenza

16. http://flexikon.doccheck.com/de/Influenza

17. http://www.md-health.com/Influenza-B.html

18. https://www.toppharm.ch/krankheitsbild/grippe

19. http://flexikon.doccheck.com/de/Influenza

20. Mehmedali Azemi Sëmundjet e traktit tretës. Pediatria pp. 711.

21. Singh, Amandeep (2010) Pediatric Emergency Medicine Practice Acute Gastroenteritis.

22. Szajewska H, Dziechciarz P (2010) Gastrointestinal infections in the pediatric population. Curr Opin Gastroenterol 26(1): 36-44.

23. http://www.ahealthhuman.com/2017/07/gastroenteritis-in-adultsdiagnosis.html

24. Webber, Roger (2009) Communicable disease epidemiology and control: a global perspective.

25. Eckardt AJ, Baumgart DC (2011) Viral gastroenteritis in adults.

26. Mehmedali Azemi Sëmundjet e traktit tretës. Pediatria pp. 716.

27. Elliott EJ (2007) Acute gastroenteritis in children.

28.https://www.merckmanuals.com/professional/ear,-nose,and-throat-disorders/oral-and-pharyngeal-disorders / tonsillopharyngitis\#v6654909

29. https://www.mayoclinic.org/diseases-conditions/tonsillitis/ symptoms-causes/syc-20378479

30. https://www.aarontrinidade.com/tonsillitis

31. Mehmedali Azemi Sëmundjet e traktit te frymëmarrjes. Pediatria pp. 561.

32. https://www.mayoclinic.org/diseases-conditions/tonsillitis/diagnosistreatment/drc-20378483

33. https://www.healthline.com/health/back-pain\#2

34. https://www.medicalnewstoday.com/articles/172943.php

35.https://www.mayoclinic.org/diseases-conditions/back-pain/ diagnosis-treatment/drc-20369911

36. https://www.chautauquastar.com/2017/11/solutions-for-back-painoh-my-aching-back-november-14/

37. https://issuu.com/interpharma/docs/gesundheitswesen_2018_d 


\section{(C) $(7)$ This work is licensed under Creative}

Submission Link: https://biomedres.us/submit-manuscript.php

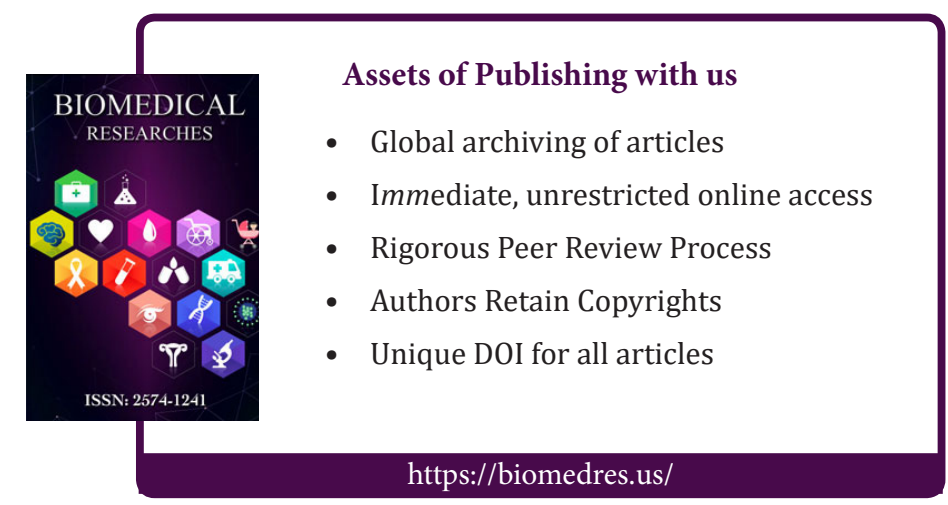

